\title{
O Banco Mundial e as Políticas Educacionais Brasileiras
}

\author{
William Pessoa da Mota Junior' \\ Olgaíses Cabral Maués' \\ 'Universidade Federal do Pará (UFPA), Belém/PA - Brasil
}

RESUMO - O Banco Mundial e as Políticas Educacionais Brasileiras. O artigo analisa o documento elaborado pelo Banco Mundial Atingindo uma educação de nível mundial no Brasil: Próximos Passos, o qual realiza um balanço dos últimos vinte anos das políticas educacionais implementadas no Brasil e traça perspectivas para os próximos anos, segundo a concepção de educação e sociedade do Banco. Este organismo internacional avalia positivamente o caráter das políticas educacionais implementadas e os resultados atingidos no período assinalado. Questiona-se e problematiza-se os critérios da avaliação, o balanço e as perspectivas traçados pelo Banco Mundial sobre a educação brasileira.

Palavras-chave: Políticas Educacionais. Banco Mundial. Brasil.

ABSTRACT - The World Bank and the Brazilian Educational Policies. The paper analyzes the document prepared by the World Bank Achieving a World-Class Education In Brazil: The Next Agenda, which performs an assessment of the last twenty years of educational policies implemented in Brazil, and outlines perspectives for the coming years, according to the Bank's conception of education and society. This international body assesses as positive the character of the implemented educational policies and the results achieved in the indicated period. The criteria of the evaluation, the assessment, and the outlined perspective by the World Bank on Brazilian education are questioned and problematized.

Keywords: Educational Policies. World Bank. Brazil.

Educação \& Realidade, Porto Alegre, v. 39, n. 4, p. 1137-1152, out./dez. 2014.1137 Disponível em: <http://www.ufrgs.br/edu_realidade> 


\section{Introdução}

Este artigo tem por objetivos analisar o balanço feito pelo Banco Mundial sobre os resultados das políticas educacionais implementadas pelo Estado brasileiro nas últimas duas décadas, bem como identificar as novas orientações propostas em termos de política educacional e os pressupostos teóricos da visão de sociedade e de educação deste organismo internacional.

Para cumprir este objetivo, realizamos análise documental da publicação do Banco Mundial sobre a educação no Brasil, o Achieving World Class Education in Brazil: The Next Agenda ${ }^{1}$ (2011), além de revisão bibliográfica de artigos publicados em língua portuguesa e outros textos complementares que tratam da relação entre o Banco e as políticas educacionais brasileiras das últimas duas décadas.

Vários estudos (Lima, 2003; Sguissardi, 2000; Leher, 1998; Coraggio, 2003; Siqueira, 2004; Kruppa, 2000) acerca das influências do Banco Mundial sobre a reforma da educação brasileira nos anos de 1990 identificam que é nessa década que se aprofundam as relações entre este organismo internacional e o governo brasileiro, o que impactou profundamente os rumos das políticas educacionais adotadas no país desde então.

No entanto, há uma necessidade de atualização das pesquisas sobre a relação entre os organismos internacionais e as políticas públicas educacionais brasileiras na primeira década do século XXI, tendo em vista que as mudanças conjunturais e estruturais na economia e na política em nosso país e no mundo refletiram consideravelmente sobre a natureza e o sentido dessas políticas.

Novos documentos foram escritos, novas categorias e discursos emergiram, novos atores entraram em cena e novas necessidades se impuseram a partir de mudanças históricas de grande importância, como o aprofundamento do processo de mundialização do capital, a localização econômica do Brasil no cenário global e a ascensão de um governo cuja caracterização política é bastante controversa, entre outras mudanças significativas que necessitam de análises atualizadas. $\mathrm{O}$ próprio documento, que é objeto de análise deste artigo, ainda não foi estudado pelos pesquisadores em educação, fato que justifica e torna relevante a presente investigação.

O artigo está estruturado em três tópicos: O Banco Mundial e as reformas educacionais no Brasil na década de 1990, onde discutimos os antecedentes das políticas implementadas na década seguinte e analisamos a natureza das relações entre o Banco Mundial e o Estado brasileiro, bem como suas consequências mais importantes para a educação em nosso país, particularmente no período do governo Fernando Henrique Cardoso (1995-2002); O balanço do Banco Mundial sobre as políticas educacionais brasileiras nas últimas duas décadas, tópico no

1138 Educação \& Realidade, Porto Alegre, v. 39, n. 4, p. 1137-1152, out./dez. 2014. Disponível em: <http://www.ufrgs.br/edu_realidade> 
qual analisamos e problematizamos a avaliação feita pelo Banco apresentada no documento Achieving World Class Education in Brazil: The Next Agenda acerca dos resultados educacionais obtidos pelo Brasil na década de 2000, em especial a partir das políticas adotadas pelo governo Lula da Silva (2003-2010); e, antes das considerações finais, um último tópico intitulado As perspectivas e os pressupostos teóricos do Banco Mundial para a educação brasileira na atualidade, quando apontamos as orientações sugeridas pelo Banco para o futuro das políticas em educação no Brasil e analisamos os pressupostos teóricos da visão de mundo e de educação dessa instituição presentes no documento citado.

\section{O Banco Mundial e as Reformas Educacionais no Brasil na Década de 1990}

Há cerca de duas décadas, organismos multilaterais como o Banco Mundial (BM), a Organização das Nações Unidas para a Educação, a Ciência e a Cultura (UNESCO), a Organização Mundial de Comércio (OMC) e a Organização para Cooperação e o Desenvolvimento Econômico (OCDE) têm orientado as políticas educacionais nos países periféricos com o objetivo de responder, dentro dos limites do campo educacional e de sua possibilidade de alcance, à crise estrutural do capitalismo desencadeada nos anos de 1970, uma vez que a educação passou a ser vista não somente como uma importante fronteira econômica a ser explorada, mas também por sua funcionalidade aos grandes capitalistas em formar uma nova geração de trabalhadores que pudessem se adequar, em termos de conhecimentos e técnicas, às novas exigências produtivas e organizacionais de um contexto marcado pela reestruturação dos processos produtivos (crise do fordismo e advento do toyotismo) e por uma forte crise no Estado capitalista.

As reformas educacionais concebidas e executadas pelo governo brasileiro nos anos 1990 foram, em particular, profundamente influenciadas pelos diagnósticos e orientações do Banco Mundial, sobretudo durante os 8 anos de governo de Fernando Henrique Cardoso (FHC) (1995-2002).

O alinhamento estratégico entre o Ministério da Educação do Brasil (MEC) e o Banco Mundial era tamanho, nesse período, que os principais quadros responsáveis pelo governo brasileiro em matéria de educação, a começar pelo ministro, já haviam feito parte do staff como diretores ou como consultores das agências que compõem o Grupo Banco Mundial e outras agências multilaterais. É o caso, por exemplo, de Paulo Renato Souza (ministro da Educação durante os dois mandatos de Fernando Henrique Cardoso), Guiomar Nano de Mello (membro do Conselho Nacional de Educação a partir de 1997 até o fim do mandato de FHC) e Cláudia Costin (ex-ministra da Administração), entre outros (Azevedo; Lara, 2011).

Educação \& Realidade, Porto Alegre, v. 39, n. 4, p. 1137-1152, out./dez. 2014. 
O Banco Mundial e as Políticas Educacionais Brasileiras

Segundo Helena Altmann (2002), no cerne das propostas do Banco Mundial para as reformas educacionais nos países periféricos, entre eles o Brasil, estavam a ênfase na educação básica ${ }^{2}$, a descentralização da gestão e a centralização da avaliação dos sistemas escolares. A ênfase na educação básica (ensino fundamental) tornou-se mais evidente a partir da criação do Fundo de Manutenção e Desenvolvimento do Ensino Fundamental e Valorização do Magistério (FUNDEF), com a lei n. 9424/96. O FUNDEF, como ficou conhecido, se constituiu em um Fundo contábil, formado por vários impostos, tendo como objetivos a remuneração condigna dos professores do ensino fundamental público, em efetivo exercício no magistério, o estímulo ao trabalho em sala de aula e a melhoria da qualidade do ensino. Essa legislação foi revogada por meio da Lei n. 11.494 de 20 de junho de 2007, que criou o FUNDEB, abrangendo toda a educação básica.

A descentralização da gestão em seus aspectos administrativos e financeiros significou a responsabilização crescente das instituições escolares pelo rendimento escolar de seus alunos, a partir de parâmetros de avaliação definidos externamente e maior racionalização nos gastos, incluindo o incentivo à captação de recursos via parcerias público-privadas e via projetos de voluntariado, como o Amigos da Escola. E a centralização dos sistemas de avaliação como forma de fixar padrões de desempenho e induzir aos resultados esperados pelas escolas e pelos alunos. É nesse contexto que são implantados o Sistema de Avaliação da Educação Básica (SAEB), de 1990, o Exame Nacional do Ensino Médio (ENEM), de 1998, e o Exame Nacional de Cursos (ENC), criado em 1995. Segundo Carlos Roberto Jamil Cury (1996), a própria LDB n. 9394/96 reflete essa perspectiva de descentralização em termos da flexibilidade do planejamento e da gestão administrativa e financeira que são repassados à escola e a forte centralização na avaliação, entendida como controle de resultados e fixação de padrões de desempenho. Com essa mudança na concepção da lei, o controle passa a não ser mais exercido na base através do currículo mínimo, da carga horária específica, etc., mas na saída, mediante a avaliação.

Esse interesse do Banco Mundial pela educação e outras áreas que vão para além de assuntos econômicos e técnico-financeiros começa a ganhar destaque a partir dos anos de 1980. Em análise sobre a agenda do Banco Mundial para as políticas educacionais e a questão da governança, Borges (2003) demarca que o balanço das políticas de ajuste estrutural, implementadas pelo Banco na África Subsaariana na década de 1980, aponta para uma reorientação na agenda e no conteúdo das políticas formuladas pelo organismo para os países periféricos em função das transformações conjunturais de escala global e do fracasso daquelas políticas em termos de impulso ao crescimento econômico, à estabilização política e à redução da pobreza. Para o autor, “[...] a agenda de políticas do Banco Mundial deslocou-se das reformas macroeconômicas stricto sensu para as reformas do Estado e da administração pú-

1140 Educação \& Realidade, Porto Alegre, v. 39, n. 4, p. 1137-1152, out./dez. 2014 Disponível em: <http://www.ufrgs.br/edu_realidade> 
blica, objetivando promover a 'boa governança' e fortalecer a sociedade civil” (Borges, 2003, p. 125). Outro aspecto que Borges cita como central para o BM é a questão referente ao combate à pobreza, esta enquanto um custo social advindo do ajuste estrutural. Nessa lógica é dado destaque à necessidade dos serviços sociais promoverem a equidade e a eficiência.

Em dois relatórios publicados no ano de 1999 (Educational change in Latin American and the Caribbean ${ }^{3}$ e Education sector strategy $y^{4}$, o Banco Mundial reconhece a importância das reformas educacionais para consolidar a democracia liberal e promover a estabilidade política. Uma população educada, pela lógica do organismo, terá maior probabilidade de mostrar interesse e envolvimento na condução política do país e, como consequência, será mais capaz de fazer escolhas corretas e cobrar a responsabilidade dos políticos quanto às promessas de campanha eleitoral (World Bank, 1999a; 1999b). Além disso, a educação promove o desenvolvimento social, aumentando a coesão da sociedade e oferecendo melhores oportunidades aos indivíduos (World Bank, 1999b, p. 5).

Assim, a reforma educacional contribuiria para a estabilidade política, na medida em que garantiria oportunidades iguais a todos os cidadãos. Diante das enormes desigualdades de renda e acesso à educação na América Latina, o Banco considera que as “[...] políticas [educacionais] de inclusão são fundamentais para aumentar a coesão da sociedade e evitar protestos e descontentamento social" (World Bank, 1999a, p. 51). Em linhas gerais, investindo e melhorando a qualidade da educação e de outros serviços sociais tornar-se-ia possível manter o apoio dos eleitores às reformas econômicas como a privatização e a liberalização comercial, o que asseguraria a estabilidade política e econômica (Burki; Edwards, 1996, p. 20).

A influência do Banco Mundial sobre as políticas educacionais no Brasil dos anos 1990 foi bastante significativa, tanto em sua concepção quanto em sua operacionalização. Sguissardi (2000) elenca e analisa exemplos e processos concretos em torno da reforma do ensino superior que confirmam o alinhamento das políticas educacionais brasileiras com a concepção de educação do BM e seu projeto para a periferia do capitalismo nos anos de 1990. Para o autor, os diagnósticos e as orientações do BM em relação à educação superior vem influenciando, no caso brasileiro, a legislação, o financiamento público, a diversificação de fontes de recursos e a natureza das instituições.

As razões decorrem da ordem econômico-política hegemônica em termos globais, em que ocorrem a mundialização do capital, a reestruturação produtiva e a crise e reforma minimalista dos Estados nacionais [...] Examinando-se as reformas tópicas em curso no Brasil, que vão da legislação (LDB, Decretos, Portarias Ministeriais, Propostas de Emendas Constitucionais sobre a autono-

Educação \& Realidade, Porto Alegre, v. 39, n. 4, p. 1137-1152, out./dez. 2014.1141 Disponível em: <http://www.ufrgs.br/edu_realidade> 
mia, contratos de gestão, projetos de desenvolvimento institucional, etc.) ao financiamento (montantes e percentuais sobre o PIB aplicados em educação superior pelo Fundo Público), passando pela questão da natureza das IES, como já demonstrado por diversos estudos, é inevitável sua associação às diretrizes e recomendações do BM (Sguissardi, 2000, p. 11-12).

Segundo Leher (1999), o Banco Mundial tornou-se uma espécie de ministério da educação dos países periféricos ao estabelecer condicionalidades em termos das políticas sociais a serem adotadas pelos países tomadores de empréstimos do Fundo Monetário Internacional (FMI) e do BM. A capacidade de emprestar recursos aos países periféricos, combinado com a assessoria técnica prestada pelo Banco, permitiu que politicamente este se tornasse o maior centro mundial de informações sobre desenvolvimento e pudesse canalizar para a órbita de influência dos Estados Unidos (EUA) a maioria dos países que estavam passando por processos de descolonização e que estavam sendo disputados pela União Soviética (URSS) (Leher, 1999).

As condicionalidades, portanto, estariam a serviço da estratégia do BM de promover o ajuste estrutural macroeconômico necessário à inserção do Brasil e demais países periféricos no processo de globalização neoliberal, o que significou, no caso do Brasil a partir do governo de Collor de Melo (1990-1992), a radicalização da liberalização da economia, com as privatizações dela decorrentes, e a destruição de um precário Estado Social por meio de uma contrarreforma do Estado, cujos efeitos mais visíveis sobre a educação básica e superior são o avanço do setor privado, a precarização do púbico e a penetração dos mecanismos e valores de mercado sobre a gestão, o financiamento, a avaliação e a produção de conhecimento.

\section{O Balanço do Banco Mundial sobre as Políticas Educacionais Brasileiras: governos Fernando Henrique Cardoso e Lula da Silva}

O documento Achieving World Class Education in Brazil: The Next Agenda, apresenta no primeiro capítulo a "Educação brasileira 19952010: Transformação”, o qual já sugere a intenção do Banco Mundial em fazer um balanço de uma década e meia de reformas educacionais no Brasil, o que abrange exatamente o período correspondente aos dois mandatos dos governos Cardoso e Lula da Silva.

Ainda no prefácio do referido documento, os autores da publicação (Bruns; Evans; Luque, 2011) iniciam o texto afirmando que "O Brasil tem realizado grandes avanços na educação ao longo dos últimos 15 anos e tem estabelecido audaciosas metas nacionais para atender aos níveis de qualidade da OCDE para 2021". Ou seja, a primeira afirmação do Banco Mundial, no documento que avalia as transformações sofri-

1142 Educação \& Realidade, Porto Alegre, v. 39, n. 4, p. 1137-1152, out./dez. 2014 Disponível em: <http://www.ufrgs.br/edu_realidade> 
das pela educação brasileira nos últimos 15 anos, atesta um balanço positivo da implementação das políticas concebidas no âmbito dos governos em colaboração com outras instituições.

O balanço apresentado no documento está baseado em algumas comparações feitas pelo BM em relação às estatísticas educacionais que tratam do aumento do número médio de anos de estudos feitos pela população brasileira em geral, em especial os mais pobres, pelo aumento da escolaridade da força de trabalho, pelo nível de formação dos professores e pelos resultados dos estudantes brasileiros no Programme for International Student Assesstment (PISA), que mede o nível de aprendizagem de estudantes matriculados nos três últimos anos do ensino fundamental ou em qualquer série do ensino médio, que tenham 15 anos de idade.

O retrato descrito pelo BM sobre a educação brasileira no início dos anos 1990 era o seguinte:

\begin{abstract}
Mas em 1990, em qualquer imaginável indicador educacional o Brasil ficava bem abaixo dos países em desenvolvimento da América Latina e perdia dramaticamente daqueles da OCDE. Somente $38 \%$ das crianças estavam matriculadas no ciclo de três anos $\left(9^{\mathrm{a}}\right.$ a $11^{\mathrm{a}}$ séries $)$ da escola secundária, em comparação com mais de $70 \%$ na Argentina e Chile e 91\% nos países da OCDE. A média de escolaridade da força de trabalho em 1990 era de 3,8 anos - menos que metade da média da Argentina, Chile e países da OCDE. Nacionalmente, menos de $20 \%$ dos professores da educação primária ${ }^{5}$ tinham ensino superior completo. O salário dos professores em muitas áreas rurais era menos da metade de um salário mínimo. Não existiam dados nacionais sobre a aprendizagem dos alunos (Bruns; Evans; Luque, 2011, p. 13).
\end{abstract}

Além da comparação entre as estatísticas educacionais dos dois períodos, os autores da publicação que estamos analisando exaltam ao longo de todo o texto os sistemas e mecanismos de avaliação constituídos nos governos Cardoso e Lula da Silva (SAEB, Prova Brasil/Provinha Brasil, IDEB, ENEM, Provão, ENADE), como exemplos internacionais de políticas que contribuem para orientar os esforços técnicos e financeiros a serem manejados pelo Estado, em particular o incentivo à meritocracia no âmbito das escolas e entre os professores. Ressalte-se que o documento utiliza a expressão "medição dos resultados" como sinônimo de avaliação em vários trechos. O documento, ao indicar a "ausência de informações sobre a aprendizagem do aluno" no início do governo FHC, ressalta o esforço que ambos, FHC e Lula, fizeram para a construção de "um dos mais impressionantes sistemas para mensurar resultados na educação". Continuando nos elogios a respeito do assunto, o BM nos informa que a Prova Brasil/Provinha Brasil e o IDEB se constituem em uma prática avaliativa "superior à prática atual dos EUA e outros países da OCDE” (Bruns; Evans; Luque, 2011, p. 13). 
Dias Sobrinho (2010) contribui com uma importante reflexão sobre o caráter das políticas de avaliação desenvolvidas pelos governos neoliberais, como aquelas levadas a cabo no Brasil no período que vai da segunda metade da década de 1990 até o final da primeira década do século XXI.

Com o advento da supremacia do neoliberalismo e as consequentes políticas de diminuição da presença do Estado nos financiamentos públicos, os exames gerais ganharam importância como instrumento de controle e de reforma. Sua dimensão política de controle passou a prevalecer sobre a pedagógica. Os exames nacionais atendem bem as finalidades de medir a eficiência e a eficácia da educação segundo os critérios e as necessidades dos Estados neoliberais, em suas reformas de modernização, e do mercado, em seu apetite por lucros e diplomas (Dias Sobrinho, 2010, p. 202).

Os desdobramentos das reformas educacionais orientadas pelos organismos internacionais como o Banco Mundial, que vêm impactando os países da América Latina há cerca de duas décadas, são tão profundos que, segundo Oliveira (2009), levaram a constituir uma nova regulação educativa, assentada em três pilares: a gestão local, o financiamento per capita e a avaliação sistêmica. Esta reflexão de Oliveira (2009) é importante para entendermos o porquê do Banco Mundial ter justamente apostado nesses 3 eixos para conduzir a reforma educacional no Brasil num contexto pós-Consenso de Washington de consolidação da doutrina neoliberal com o processo de Reforma do Estado.

Os déficits estruturais da situação educacional brasileira, com altas taxas de analfabetismo, baixas taxas de escolarização em todos os níveis de ensino, a carência de qualificação da força de trabalho para o desenvolvimento econômico e a transição política instável dos anos 1980 para os anos 1990, impuseram ao Banco uma necessidade de resposta em termos de políticas e reformas ao drama educacional do país sem que essa resposta significasse um aumento de gastos públicos e maior responsabilização do Estado com o setor.

Só no ensino superior, houve uma redução entre 1989 e 2006 nos investimentos da União no setor como percentual do PIB, de 0,97\% para $0,62 \%$, conforme atesta a Tabela 1 .

1144 Educação \& Realidade, Porto Alegre, v. 39, n. 4, p. 1137-1152, out./dez. 2014. Disponível em: <http://www.ufrgs.br/edu_realidade> 
Tabela 1 - Recursos das IFES como Percentual do PIB, das Despesas Correntes do FPF e da Arrecadação de Impostos da União (1989-2006)

Valores em R\$ milhões, a preços de janeiro de 2007 (IGP-DI/FGV)

\begin{tabular}{|c|c|c|c|c|c|c|}
\hline \multirow[b]{2}{*}{ PIB } & \multirow[b]{2}{*}{ Despesas } & \multirow{2}{*}{$\begin{array}{c}\text { IMPOSTOS } \\
\text { Correntes } \\
\text { do FPF }\end{array}$} & \multicolumn{4}{|c|}{ IFES } \\
\hline & & & Recursos & $\% \mathrm{PIB}$ & $\% \mathrm{FPF}$ & \%Impostos \\
\hline 1.756 .061 .009 & 287.880 & 136.388 & 17.027 & 0,97 & 5,91 & 12,5 \\
\hline 1.757 .030 .199 & 286.686 & 168.568 & 13.859 & 0,79 & 4,83 & 8,2 \\
\hline 1.785.794.719 & 208.378 & 117.419 & 10.908 & 0,61 & 5,23 & 9,3 \\
\hline 1.740 .201 .792 & 230.359 & 70.937 & 9.801 & 0,57 & 4,28 & 13,9 \\
\hline 1.736 .955 .061 & 295.912 & 130.102 & 12.807 & 0,74 & 4,33 & 9,8 \\
\hline 1.716 .357 .111 & 285.966 & 173.764 & 15.573 & 0,91 & 5,45 & 9,0 \\
\hline 2.071 .126 .370 & 326.762 & 149.282 & 16.700 & 0,81 & 5,11 & 11,2 \\
\hline 2.229 .733 .565 & 337.549 & 149.390 & 15.067 & 0,68 & 4,46 & 10,1 \\
\hline 2.299 .278 .708 & 346.165 & 152.997 & 14.802 & 0,64 & 4,28 & 9,7 \\
\hline 2.307 .815 .657 & 381.385 & 170.702 & 14.534 & 0,63 & 3,81 & 8,5 \\
\hline 2.254 .630 .092 & 394.647 & 171.657 & 14.232 & 0,63 & 3,61 & 8,3 \\
\hline 2.194 .743 .789 & 369.225 & 156.565 & 13.416 & 0,61 & 3,63 & 8,6 \\
\hline 2.195 .491 .997 & 394.346 & 163.994 & 12.277 & 0,56 & 3,11 & 7,5 \\
\hline 2.195 .253 .919 & 389.950 & 175.044 & 12.484 & 0,57 & 3,20 & 7,1 \\
\hline 2.056 .406 .744 & 367.411 & 151.908 & 11.080 & 0,54 & 3,02 & 7,3 \\
\hline 2.146 .770 .261 & 384.103 & 155.209 & 12.264 & 0,57 & 3,19 & 7,9 \\
\hline 2.241 .336 .605 & 418.252 & 173.692 & 11.865 & 0,53 & 2,84 & 6,8 \\
\hline 2.382 .711 .481 & 516.778 & 187.441 & 14.706 & 0,62 & 2,85 & 7,8 \\
\hline
\end{tabular}

Fonte: PIB: Banco Central do Brasil e IPEA - http://www.ipeadata.gov.br; Impostos: Arrecadação da Receita Administrativa pela SRF - http://www.receita.fazenda.gov.br; Recursos das IFES: 1989-1994: MF/STN/CGC: 1995-2006: Execução Orçamentária da União - http://www.camara.gov.br; Desp.

Correntes do FPF: Execução Orçamentária do Governo Federal e Balanço Geral da União.

Em relação ao investimento global do Estado brasileiro com Educação, iniciou-se uma recomposição no percentual do Produto Interno Bruto destinado ao setor, extremamente incipiente na década de 2000. Houve um crescimento de apenas $1,2 \%$ do PIB em uma década, conforme aponta a tabela 2, percentual absolutamente insuficiente diante dos desafios educacionais em nosso país.

Tabela 2 - Percentual do Investimento Público Direto em Educação em Relação PIB (2000-2010)

\begin{tabular}{|c|c|c|c|c|c|c|c|}
\hline \multirow{4}{*}{ Ano } & \multicolumn{7}{|c|}{ Percentual do Investimento Público Direto em relação ao PIB (\%) } \\
\hline & \multirow{3}{*}{$\begin{array}{l}\text { Todas } \\
\text { as } \\
\text { Etapas } \\
\text { de } \\
\text { Ensino }\end{array}$} & \multicolumn{6}{|c|}{ Etapa de Ensino } \\
\hline & & \multirow[b]{2}{*}{$\begin{array}{c}\text { Educação } \\
\text { Básica }\end{array}$} & \multirow[b]{2}{*}{$\begin{array}{c}\text { Educação } \\
\text { Infantil }\end{array}$} & \multicolumn{2}{|c|}{ Ensino Fundamental } & \multirow[b]{2}{*}{$\begin{array}{l}\text { Ensino } \\
\text { Médio }\end{array}$} & \multirow[b]{2}{*}{$\begin{array}{l}\text { Ensino } \\
\text { Superior }\end{array}$} \\
\hline & & & & $\begin{array}{c}\text { De } 1^{\mathrm{a}} \mathrm{a} 4^{\mathrm{a}} \\
\text { séries ou } \\
\text { anosiniciais }\end{array}$ & $\begin{array}{c}\text { De } 5^{\mathrm{a}} \text { a } 9^{\circ} \\
\text { séries ou } \\
\text { anos finais }\end{array}$ & & \\
\hline 2000 & 3,9 & 3,2 & 0,3 & 1,3 & 1,1 & 0,5 & 0,7 \\
\hline 2001 & 4,0 & 3,3 & 0,3 & 1,3 & 1,1 & 0,6 & 0,7 \\
\hline 2002 & 4,1 & 3,3 & 0,3 & 1,5 & 1,1 & 0,4 & 0,8 \\
\hline 2003 & 3,9 & 3,2 & 0,3 & 1,3 & 1,0 & 0,5 & 0,7 \\
\hline 2004 & 3,9 & 3,2 & 0,3 & 1,3 & 1,1 & 0,5 & 0,7 \\
\hline 2005 & 3,9 & 3,2 & 0,3 & 1,4 & 1,1 & 0,4 & 0,7 \\
\hline 2006 & 4,3 & 3,6 & 0,3 & 1,4 & 1,3 & 0,6 & 0,7 \\
\hline 2007 & 4,5 & 3,8 & 0,4 & 1,5 & 1,4 & 0,6 & 0,7 \\
\hline 2008 & 4,7 & 4,0 & 0,4 & 1,5 & 1,5 & 0,7 & 0,7 \\
\hline 2009 & 5,0 & 4,2 & 0,4 & 1,6 & 1,6 & 0,7 & 0,7 \\
\hline 2010 & 5,1 & 4,3 & 0,4 & 1,6 & 1,5 & 0,8 & 0,8 \\
\hline
\end{tabular}

Educação \& Realidade, Porto Alegre, v. 39, n. 4, p. 1137-1152, out./dez. 2014.

Disponível em: <http://www.ufrgs.br/edu_realidade> 
O Banco Mundial e as Políticas Educacionais Brasileiras

O balanço dos intelectuais críticos, ligados aos movimentos sociais em defesa da educação pública, em relação à primeira década do século XXI, é oposto ao do Banco Mundial, pois as continuidades em termos de caráter e objetivos das políticas educacionais entre os governos de Fernando Henrique Cardoso e Lula da Silva foram muito mais fortes e permanentes do que se podia esperar na transição de governo. Os índices de analfabetismo e a não-universalização da educação pública em todos os níveis de ensino seguem sendo duas chagas ainda não superadas, sem contar o avanço da privatização e da mercantilização deste direito fundamental, que hoje é negociado nas bolsas de valores e que a cada dia que passa apresenta sinais mais nítidos da incapacidade de formação humana das novas gerações, com a escalada crescente de violência nas escolas e os altos índices de analfabetismo funcional. Frigotto (2011) realizou um balanço da década passada, no que se refere à educação em nosso país, e aponta caminhos para reflexão que colocam em xeque toda a euforia do Banco Mundial que é objeto de análise neste texto.

\begin{abstract}
No plano das políticas educacionais, da educação básica à pós-graduação, resulta, paradoxalmente, que as concepções e práticas educacionais vigentes na década de 1990 definem dominantemente a primeira década do século XXI, afirmando as parcerias do público e privado, ampliando a dualidade estrutural da educação e penetrando, de forma ampla, mormente nas instituições educativas públicas, mas não só, e na educação básica, abrangendo desde o conteúdo do conhecimento até os métodos de sua produção ou socialização (Frigotto, 2011, p. 242).
\end{abstract}

Vê-se, pois, que no âmbito da gestão (empresariamento da gestão através das parcerias público-privadas, dos contratos de gestão e da descentralização), do financiamento (manutenção dos padrões de financiamento como percentual do PIB em educação nas últimas duas décadas) e da avaliação (entendida como instrumento regulação e controle), o tripé da nova regulação educacional na América Latina e no Brasil, é possível identificar as principais transformações operadas na educação brasileira. Os intelectuais orgânicos do Capital, como o Banco Mundial, fazem um balanço positivo dos resultados das políticas. Os autores ligados e alinhados aos movimentos sociais que fazem a crítica da concepção de educação e sociedade constitutiva das políticas oficiais apresentam uma avaliação oposta, embora ambos identifiquem os mesmos elementos como aqueles centrais das transformações pelas quais passam a educação no Brasil.

\title{
As Perspectivas e os Pressupostos Teóricos do Banco Mundial para a Educação Brasileira na Atualidade
}

O objetivo do Banco Mundial com a elaboração do documento Achieving World Class Education in Brazil: The Next Agenda não é apenas

1146 Educação \& Realidade, Porto Alegre, v. 39, n. 4, p. 1137-1152, out./dez. 2014 Disponível em: <http://www.ufrgs.br/edu_realidade> 
o de descrever as mudanças processadas na educação brasileira nos últimos 15 anos, nem tampouco o de fazer um mero elogio desinteressado das políticas e reformas educacionais implementadas pelos últimos governos, mas há também uma motivação política, que é exatamente a de seguir orientando o caráter e os rumos das políticas educacionais no país no sentido de manter e aprofundar a hegemonia de seu modelo de educação e sociedade em todo o mundo.

O próprio Sumário Executivo do documento deixa essa intenção clara quando afirma em seu início:

\begin{abstract}
Realizando uma avaliação comparativa do desempenho atual da educação e identificando as questões chaves no Brasil, o estudo foi concebido como um recurso que poderá ser utilizado pela nova administração federal para definir prioridades para a educação nos próximos 4 anos. Mas, o estudo também analisa a notável trajetória brasileira de continuidade de políticas e reformas sustentadas na educação durante os últimos 15 anos (Banco Mundial, 2010, p. 02, grifos nossos).
\end{abstract}

É bastante visível no documento uma certa perspectiva economicista do papel da educação, seja em relação à sua função social enquanto formadora de mão de obra para atender às exigências da economia capitalista do século XXI, seja em relação ao lugar que ela deve ocupar como política pública e a relação que deve estabelecer com o Estado, a iniciativa privada e o orçamento público. Para esse organismo internacional, o sistema educacional deve desempenhar três papéis, considerados como primordiais, quais sejam: o desenvolvimento de "habilidades da força de trabalho para sustentar o crescimento econômico", a contribuição “para a redução da pobreza e desigualdade”, buscando oferecer oportunidade educacional para todos e, por fim, porém mais importante, o sistema deve estar voltado para o papel de "transformar gastos na educação em resultados educacionais” (Banco Mundial, 2010, p. 23).

Vê-se, pois, que o crescimento econômico deve ser o grande objetivo de um sistema educacional para o Banco. Essa concepção está profundamente impregnada da Teoria do Capital Humano, como o próprio BM reivindica, quando defende que as pesquisas internacionais têm demonstrado que o capital humano, considerado como a média de escolaridade da força de trabalho, é um elemento crítico para esse crescimento (Banco Mundial, 2010, p. 23).

Frigotto (2000) afirma que a ideia central da teoria do capital humano é a de que um acréscimo marginal de instrução, treinamento e educação, correspondem um acréscimo marginal de capacidade de produção. A ideia do Capital Humano é uma quantidade ou um grau de educação e de qualificação, tomado como indicativo a um determinado volume de conhecimentos, habilidades e atitudes adquiridas, que fun-

Educação \& Realidade, Porto Alegre, v. 39, n. 4, p. 1137-1152, out./dez. 2014.1147 Disponível em: <http://www.ufrgs.br/edu_realidade> 
O Banco Mundial e as Políticas Educacionais Brasileiras

cionam como potencializadoras da capacidade de trabalho e produção. Assim, o mito amplamente difundido na sociedade de que a educação seria a grande panaceia para superar a pobreza e as desigualdades sociais em termos tanto macro como microeconômicos, tem suas raízes fincadas nessa teoria.

Outra questão importante a ser assinalada a propósito da concepção de educação do BM é que se mantém nesse documento a compreensão de que a educação é o instrumento privilegiado para o alívio da pobreza e manutenção da estabilidade política.

\begin{abstract}
O amplo acesso à educação não só desenvolve as habilidades da força de trabalho; isso gera subsídios para uma sociedade mais igualitária. Os sistemas de ensino que permitem o desenvolvimento de indivíduos talentosos e motivados oriundos de todas as camadas da sociedade desenvolvem mais habilidades, profissões e renda, com a promessa de mobilidade social ascendente. O Brasil tem sido historicamente um dos países com mais desigualdades do mundo. No índice de Gini no qual as nações europeias e Canadá pontuaram entre 0,24 e 0,36 (com 0 indicando perfeita igualdade), a estimativa para o Brasil em 1993 foi de 0,52. Paes de Barros (2000) concluiu que 2/3 (dois terços) da desigualdade salarial brasileira poderia ser atribuída ao acesso desigual à educação (Bruns; Evans; Luque, 2011, p. 35).
\end{abstract}

Tais proposições revelam a perspectiva (neo)liberal defendida pelo Banco em relação ao papel do Estado. No Brasil, como assinalamos, essa concepção de educação dos organismos internacionais se difunde por meio da Reforma do Estado e por legislações complementares. O diagnóstico do então Ministério da Administração e Reforma do Estado (MARE) sobre a crise internacional e nacional dos anos 1990 centrava-se nas funções que o Estado cumpria em suas relações com a Sociedade (esfera pública e privada).

Silva Junior (2005), ao fazer uma análise crítica a respeito da Reforma do Estado, indica algumas das suas finalidades, tais como a superação da crise fiscal que estaria impedindo ter uma poupança pública sólida capaz de estabilizar os preços e financiar os investimentos, a alteração da estrutura do aparelho estatal (deixando de ser patrimonialista e burocrático) e de pessoal que estaria impedindo que os serviços fossem mais baratos e de melhor qualidade, além de mudança no tocante à intervenção do Estado no plano econômico e social.

Essas finalidades da Reforma demonstram que o MARE considerava a crise do Estado a causa básica da crise econômica pela qual o país vinha passando. Por crise fiscal se entende a perda do crédito público e a poupança pública negativa. Por crise do modo de intervenção, o esgotamento do modelo protecionista de substituição de importações e, finalmente, por crise do aparelho do Estado, entende o clientelismo, a

1148 Educação \& Realidade, Porto Alegre, v. 39, n. 4, p. 1137-1152, out./dez. 2014 Disponível em: <http://www.ufrgs.br/edu_realidade> 
profissionalização insuficiente e o enrijecimento burocrático extremo da Constituição de 1988.

Em decorrência de todos esses posicionamentos, seria óbvio que, em relação ao financiamento, o Banco Mundial argumentasse que o problema da educação no Brasil não fosse de falta de recursos financeiros, mas de problemas na sua gestão. Além de defender que o país gasta muito com educação superior e que perde muitos recursos com a corrupção, o Banco se alinha ao setor privado na atual polêmica sobre o patamar de investimentos em relação ao PIB que o Brasil deve investir na educação durante a vigência do Plano Nacional de Educação, que está em discussão no Congresso Nacional:

O Ministério da Educação do Brasil e o apoio à coalizão público-privada 'Educação para Todos' (Education for All) comprometeram-se a gastar no limite de $7 \%$ do PIB até 2015. Os líderes sindicais do Brasil solicitam uma meta nacional de $10 \%$ do PIB. As comparações com dados mundiais sugerem que esses níveis de investimento são extremamente elevados. Mais importante ainda é que os dados mundiais sugerem que usar a limitação de gastos como parâmetro, ao invés de resultados, pode ser uma estratégia incerta para o progresso da educação (Bruns; Evans; Luque, 2011, p. 45).

A defesa dos 7\% do PIB para a educação (somados os investimentos nas esferas pública e privada, é importante enfatizar), o discurso da racionalização financeira em termos de eficiência e eficácia na alocação de recursos e tendo como parâmetro de avaliação testes padronizados em larga escala com critérios de mercado e o apelo à parceria com o setor privado, demonstram, de forma inequívoca, que o lugar reservado à educação no Brasil, dentro dos planos políticos e econômicos do Banco Mundial, deve ser o de insumo ao crescimento econômico e ao aumento da produtividade do trabalho, reafirmando os pressupostos da Teoria do Capital Humano como base para sua concepção de educação.

\section{Considerações Finais}

A educação de nível mundial que o Brasil supostamente estaria atingindo, por meio das políticas adotadas pelos governos Cardoso e Lula da Silva, adota como critérios de qualidade, para a sustentação da avaliação feita no documento analisado, sobretudo a evolução dos indicadores educacionais no período assinalado no tocante às taxas de analfabetismo, de escolarização líquida e bruta e de anos de escolaridade da força de trabalho.

Além desses dados, o Banco Mundial exalta, desde uma perspectiva qualitativa, os sistemas de avaliação de aprendizagem e institucional elaborados e implementados no período assinalado. Tudo isso (a evolução das estatísticas e dos sistemas de avaliação) sem ampliação significativa dos custos financeiros para o Estado.

Educação \& Realidade, Porto Alegre, v. 39, n. 4, p. 1137-1152, out./dez. 2014.1149

Disponível em: <http://www.ufrgs.br/edu_realidade> 
A evolução dos indicadores é inegável, porém, é preciso problematizar os supostos avanços qualitativos reivindicados pelo Banco Mundial, pois os altos índices de analfabetismo funcional, mesmo que diante de uma redução no analfabetismo absoluto, os baixos resultados dos estudantes e escolas brasileiros nas avaliações nacionais e internacionais (as mesmas cuja concepção e finalidade são reivindicadas pelo Banco), o crescimento da violência nas escolas, os baixos salários dos trabalhadores em educação e a manutenção de problemas históricos e estruturais relacionados ao financiamento público e à precarização das condições de trabalho, entre outros, são elementos da realidade que nos permitem relativizar e questionar a suposta educação de nível mundial que o Brasil estaria atingindo.

O documento Achieving World Class Education in Brazil: The Next Agenda realiza um balanço de quase duas décadas de reformas educacionais e traça novas orientações para que o atual governo siga os caminhos apontados pela regulação educacional, desde meados da década de 1990, fincada no tripé financiamento per capita, avaliação sistêmica e gestão local, para que os resultados educacionais brasileiros nas avaliações internacionais como o PISA e as estatísticas de escolarização atinjam os padrões dos países da OCDE.

Estas proposições expressam uma concepção burguesa de sociedade e de educação. Os valores liberais fundamentam sua estratégia de consolidação do Estado Neoliberal no Brasil e de conformação de um modelo de educação baseado na Teoria do Capital Humano, indispensável para a manutenção da ordem geopolítica internacional.

Recebido em 02 de julho de 2013 Aprovado em 10 de maio de 2014

\section{Notas}

1 Atingindo uma educação de nível mundial: próximos passos. Tradução de Amanda Monte.

2 Para o BM a educação básica inclui apenas o ensino fundamental, no caso brasileiro.

3 Mudança educacional na América Latina e Caribe.

4 Educação - setor estratégico.

5 Refere-se as quatro primeiras séries do Ensino Fundamental.

\section{Referências}

ALTMANN, Helena. Influências do Banco Mundial no projeto educacional brasileiro. Educação e Pesquisa, São Paulo, v. 28, n. 1, jan./jun. 2002. Disponível em: <http://www.scielo.br/scielo.php?script=sci_arttext\&pid=S1517-97022002000100005\&lng=pt\&nrm=iso\&tlng=pt >. Acesso em: 08 jan. 2013.

AZEVEDO, Mário; LARA, Ângela (Org.). Políticas para a Educação: análises e apontamentos. Maringá: EDUEM, 2011.

1150 Educação \& Realidade, Porto Alegre, v. 39, n. 4, p. 1137-1152, out./dez. 2014 Disponível em: <http://www.ufrgs.br/edu_realidade> 
BANCO MUNDIAL. Atingindo uma Educação de Nível Mundial no Brasil: próximos passos - sumário executivo. 2010. Disponível em: <http://cenpec.org.br/ biblioteca/educacao/estudos-e-pesquisas/achieving-world-class-education-in-brazil-the-next-agenda>. Acesso em: 01 dez. 2012.

BORGES, André. Governança e Política Educacional: a agenda recente do banco mundial. Revista Brasileira de Ciências Sociais, São Paulo, v. 18, n. 52, jun. 2003. Disponível em: <http://www.scielo.br/scielo.php?script=sci_ arttext\&pid=S0102-69092003000200007\&lng=pt\&nrm=iso $>$. Acesso em: 22 ago. 2011.

BRUNS, Barbara; EVANS, David; LUQUE, Javier. Atingindo uma Educação de Nível Mundial no Brasil: próximos passos. Tradução de Amanda Monte. Publicações Banco Mundial. Mimeo, 2011.

BURKI, Shahid Javed; EDWARDS, Sebastian. Dismantling the Populist State: the unfinished revolution in Latin America and the Caribbean. Washington D.C., World Bank, 1996.

CORAGGIO, José Luis. Propostas do Banco Mundial para a Educação: sentido oculto ou problema de concepção? In: TOMMASI, Livia; WARDE, Mirian Jorge; HADDAD, Sérgio (Org.). O Banco Mundial e as Políticas Educacionais. São Paulo: Cortez, 2003. P. 75-124.

CURY, Carlos Roberto Jamil. Os Parâmetros Curriculares Nacionais e o Ensino Fundamental. Revista Brasileira de Educação, Rio de Janeiro, n. 2, p. 4-17, maio/ ago. 1996.

DIAS SOBRINHO, José. Avaliação e Transformações da Educação Superior Brasileira (1995-2009): do provão ao Sinaes. Avaliação (Campinas), Sorocaba, v. 15, n. 1, 2010. Disponível em: <http://www.scielo.br/scielo.php?script=sci arttext\&pid=S1414-40772010000100011\&lng=pt\&nrm=iso\&tlng=pt>. Acesso em: 08 jan. 2013.

FRIGOTTO, Gaudêncio. Educação e a Crise do Capitalismo Real. São Paulo: Cortez, 2000

FRIGOTTO, Gaudêncio. Os Circuitos da História e o Balanço da Educação no Brasil na Primeira Década do Século XXI. Revista Brasileira de Educação, Rio de Janeiro, v. 16, n. 46, p. 235-254, jan./abr. 2011.

KRUPPA, Sônia Maria Portela. O Banco Mundial e as Políticas de Educação nos anos 90. 2000. 382 f. Tese (Doutorado em Educação) - Faculdade de Educação da Universidade de São Paulo, São Paulo, 2000.

LEHER, Roberto. Da Ideologia do Desenvolvimento à Ideologia da Globalização: a educação como estratégia do Banco Mundial para "alívio" da pobreza. 1998. Tese (Doutorado em Educação) - Universidade de São Paulo, São Paulo, 1998.

LEHER, Roberto. Um Novo Senhor da Educação? A política educacional do Banco Mundial para a periferia do capitalismo. Outubro, São Paulo, v. 1, n. 3, p. 19-30, 1999

LIMA, Kátia. Organismos Internacionais e Política de Educação Superior na Periferia do Capitalismo. GT 11 - Política de Educação Superior. In: $26^{\circ}$ REUNIÃO ANUAL DA ANPED. 2003. Disponível em: <www.anped.org.br/reunioes/26/trabalhos/katiareginadesouzalima.doc >. Acesso em: 01 set. 2013.

OLIVEIRA, Dalila Andrade. Política Educacional e Regulação no Contexto Latino-americano: Argentina, Brasil e Chile. Linhas Críticas (UnB), Brasília, v. 15, n. 28, p. 45-62, jan./jun. 2009.

Educação \& Realidade, Porto Alegre, v. 39, n. 4, p. 1137-1152, out./dez. 2014 
SGUISSARDI, Valdemar. O Banco Mundial e a Educação Superior: revisando teses e posições. Universidade e Sociedade, Brasília, n. 22, p. 66-75, nov. 2000.

SILVA JUNIOR, João dos Reis. A Racionalidade Mercantil da Pós-graduação. A produção da ciência pragmática e do individualismo profissional. In: QUARTIERO, Elisa Maria; BIANCHETTI, Lucídio (Org.). Educação Corporativa. Mundo do trabalho e do conhecimento: Aproximações. Sta. Cruz do Sul: EDUNISC e São Paulo: Cortez, 2005. P. 288-312.

SIQUEIRA, Ângela C. de. A Regulamentação do Enfoque Comercial no Setor Educacional via OMC/GATS. Revista Brasileira de Educação, Rio de Janeiro, n. 26, ago. 2004. Disponível em: <http://www.scielo.br/scielo.php?script=sci_ arttext\&pid=S1413-24782004000200012\&lng=pt\&nrm=iso\&tlng=pt>. Acesso em: 08 jan. 2013.

WORLD BANK. Educational Change in LatinAmerica and the Caribbean. Washington, D. C., World Bank, 1999a. Disponível em: <http://www.worldbank. org>. Acesso em: 19 dez. 2012.

WORLD BANK. Education Sector Strategy. Washington, D.C., World Bank, 1999b. Disponível em: <http://www.worldbank.org>. Acesso em: 19 dez. 2012.

William Pessoa da Mota Junior é graduado em Ciências Sociais pela UFPA. Mestre em Educação pelo Programa de Pós-Graduação em Educação da UFPA. Doutorando em Educação.

E-mail: will_mota@yahoo.com.br

Olgaíses Cabral Maués é doutora em Ciências da Educação pela Universidade de Ciências e Tecnologia de Lille III (França) e Professora do Programa de Pós-Graduação em Educação da Universidade Federal do Pará.

E-mail: olgaises@uol.com.br 